\title{
Análise temporal do comportamento da precipitação pluviométrica na Região Metropolitana do Cariri (Ce), Brasil
}

\author{
Temporal analysis of rainfall precipitation behavior \\ in the Metropolitan Region of Cariri (MRC), Brazil
}

\section{Análisis temporal del comportamiento de la precipitación pluviométrica en la Región Metropolitana de Cariri (Ce), Brasil}

\author{
Sostenes Gomes de Sousal \\ Universidade Estácio de Sá (UNESA), Brasil
}

\begin{abstract}
Resumo
O semiárido brasileiro engloba 1.133 municípios, ocupando uma área de $982.563,3 \mathrm{~km}^{2}$ e uma população de aproximadamente 47 milhões de habitantes. A escassez hídrica no semiárido brasileiro e principalmente na região nordeste é um problema que as pessoas que residem nessas áreas enfrentam ano após ano. Essa região é caracterizada por ter: quase oito meses de ausência de chuvas que ocorrem anualmente, secas periódicas e cheias frequentes dos rios intermitentes, solos arenosos, rasos, salinos e pobres em nutrientes essenciais ao desenvolvimento das plantas. A chuva ainda representa a única fonte de realimentação dos cursos dos rios e dos aquíferos do Nordeste. O estudo de séries de chuvas é fundamental para o manejo dos recursos hídricos, desenvolvimento de projetos de convivência com o semiárido e melhores para o desenvolvimento da agropecuária, além de incentivar a sustentabilidade hídrica da região. O objetivo deste estudo foi analisar o comportamento das precipitações ocorridas nos últimos 31 anos (1987 - 2017) na Região Metropolitana do Cariri (CE), Brasil, com vistas a identificar as características sobre o regime de chuvas regional.
\end{abstract}

1 Pós-graduando em Gestão Ambiental de Empresas pela Universidade Estácio de Sá (UNESA) e Graduado em Engenharia Ambiental pelo Instituto Federal de Educação, Ciência e Tecnologia do Ceará (2016). Email: sostenes-sousa@hotmail.com 
Foram levantados junto a Fundação Cearense de Meteorologia e Recursos Hídricos (FUNCEME), dados pluviométricos mensais de uma série história do município. Realizou-se cálculos de parâmetros, como: média, máximo, mínimo e desvio padrão. Desta forma, foi possível constatar que os municípios que apresentaram os maiores índices pluviométricos são Caririaçu que no ano de 2008 alcançou 1632,0 mm e Santana do Cariri com 1612,1 mm em 1996. Vale ressaltar que entre os de 2016 e 2017 na maioria dos munícios da RMC a precipitação anual foi bem abaixo da média para a serie adotada.

Palavras-chave: Escassez hídrica; Chuvas; Manejo; Sustentabilidade.

\begin{abstract}
The Brazilian semi-arid region encompasses 1,133 municipalities, occupying an area of 982,563.3 $\mathrm{km}^{2}$ and a population of approximately 47 million inhabitants. Water scarcity in the Brazilian semiarid and mainly in the northeast region is a problem residents face year after year. This region is characterized by having: almost eight months of rainfall absence; periodic droughts; frequent flooding of intermittent rivers and sandy, shallow, saline soils deficient in essential nutrients for the development of plants. Rain still represents the only reconstituent water source that feedsback river courses and recharges aquifers of the Northeast region. The study of rainfall series is fundamental for the management of water resources, development of projects of coexistence in the semi-arid regions and improvements for the development of agriculture and livestock, besides encouraging the region's water sustainability. The objective of this study was to analyze rainfall behavior occurring in the last 31 years (1987-2017) in the Metropolitan Region of Cariri (MRC), Brazil, in view of identifying the characteristics of the regional rainfall regime. Along with the Cearense Foundation of Meteorology and Water Resources (FUNCEME), a monthly pluviometric data registry of the municipality was created based on historical data series. Parameter calculations were performed, such as: average, maximum, minimum and standard deviation. In this way, it was possible to verify that the municipalities that presented the highest rainfall indexes were Caririaçu, which registered $1632.0 \mathrm{~mm}$ in 2008 and Santana do Cariri with $1612.1 \mathrm{~mm}$ in 1996. It is worth noting that between 2016 and 2017 the annual rainfall received in most MRC municipalities was well below the average of the analyzed series.
\end{abstract}

Keywords: water scarcity; the rain; management; sustainability

\title{
Resumen
}

El semiárido brasileño engloba 1.133 municipios, ocupando un área de $982.563,3 \mathrm{~km}^{2}$ y una población de aproximadamente 47 millones de habitantes. La escasez hídrica en el semiárido brasileño y principalmente en la región nordeste es un problema que las personas que residen en esas áreas enfrentan año tras año. Esta región se caracteriza por tener: casi ocho meses de ausencia de lluvias que ocurren anualmente, sequías periódicas y llenas frecuentes de los ríos intermitentes, suelos arenosos, bajos, salinos y pobres en nutrientes esenciales para el desarrollo de las plantas. La lluvia todavía representa la única fuente de realimentación de los cursos de los ríos y de los acuíferos del Nordeste. El estudio de series de lluvias es fundamental para el manejo de los recursos hídricos, desarrollo de proyectos de convivencia con el semiárido y mejores para el desarrollo de la agropecuaria, además de incentivar la sostenibilidad hídrica de la región. El objetivo de este estudio fue analizar el comportamiento de las precipitaciones ocurridas en los últimos 31 años (1987 - 2017) en la Región Metropolitana del Cariri (CE), Brasil, con miras a identificar las características sobre el régimen de lluvias regional. Se levantaron junto a la Fundación Cearense de Meteorología y Recursos Hídricos (FUNCEME), datos pluviométricos mensuales de una serie histórica del municipio. 
Se realizaron cálculos de parámetros, como: promedio, máximo, mínimo y desviación estándar. De esta forma, fue posible constatar que los municipios que presentaron los mayores índices pluviométricos son Caririaçu que en el año 2008 alcanzó 1632,0 mm y Santana do Cariri con 1612,1 mm en 1996. Vale resaltar que entre los de 2016 y 2017 en la mayoría de los municipios de la RMC la precipitación anual fue muy por debajo de la media para la serie adoptada.

Palabras clave: escasez hídrica; la lluvia; gestión; sostenibilidad.

\section{Introdução}

A ciência da climatologia é fundamental para entender e monitorar as atividades atmosféricas sendo essas, local, regional ou mundial (Feil, 2014). Através dos dados coletados por meio de equipamentos climatológicos, é possível realizar previsões e visualizações de padrões climáticos que são de extrema importância para moldar e descrever o clima, sendo este um fator primordial para a formação do meio ambiente. (Oliveira et al, 2012).

O estudo das variabilidades da precipitação é atualmente um desafio na área de recursos hídricos (Sousa et al. 2012), especialmente devido à elevada importância sobre os efeitos da disponibilidade hídrica em bacias hidrográficas, sobretudo aquelas situadas em regiões semiáridas ou de transição (Francisco, 2004), como é o caso da Região Metropolitana do Cariri.

O diagnóstico de séries temporais de precipitação pluviométricas funciona como uma ferramenta de planejamento e pesquisa para as mais diversas áreas. O emprego desta técnica permite avaliar as anormalidades, as tendências e os impactos das chuvas em uma determinada região (Costa, Becker e Brito, 2013; Filho e Araújo, 2015).

O monitoramento e análise do comportamento das chuvas na Região Nordeste, se reveste de ampla importância, não exclusivamente sob o aspecto estritamente climático, mas, também, pelas implicações de ordem econômica e social resultantes desse fenômeno, devido dentre outros fatores a sua espantosa anormalidade no decorrer do ano (Xavier e Dornellas, 2005).

Localizada no Semiárido Nordestino, a Região Metropolitana do Cariri (RMC) é um dos principais centros do interior do Ceará. Contando com uma população de aproximadamente 601.817 habitantes (IBGE, 2017) e sofrendo um intenso processo de urbanização nas últimas décadas, a região convive com os benefícios e com os problemas decorrentes desse processo, que nem sempre é precedido por um planejamento eficiente.

Criada em 2009 pelo Governo do Estado do Ceará, a RMC veio como uma opção de minimização das discrepâncias socioeconômicas 
acentuadas existentes entre Região Metropolitana de Fortaleza e o interior do Estado. (Nascimento, 2015).

A região tem elevado potencial de desenvolvimento econômico com ênfase para os municípios que compõem o Triângulo CRAJUBAR - Crato, Juazeiro do Norte e Barbalha (Nascimento, 2015). Avaliados como centros urbanos secundários no interior do Estado do Ceará por agruparem a maior parte do contingente populacional e apresentarem os melhores indicadores socioeconômicos regionais. Além de comportarem grandes Universidades e Institutos Federais.

Neste contexto, este estudo tem por finalidade analisar o comportamento da precipitação durante 31 anos, correspondentes ao intervalo entre 1987 e 2017, na Região Metropolitana do Cariri - CE, que está localizada no Semiárido Nordestino.

\section{Considerações Gerais}

O clima é extremamente importante para a dinâmica do meio ambiente, sendo considerado um elemento condicionador em diversos aspectos, pois exerce influência direta nos processos tanto de ordem física quanto biológica, assim como na sociedade de um modo geral, visto que constitui um recurso essencial para a vida e para as atividades humanas (Christofoletti, 1993; Ripoli e Ferreira, 2014).

As variações e flutuações constantes das condições climáticas, têm elevado as pesquisas científicas que visam à quantificação e o monitoramento mais preciso de variáveis ambientais (Romani et al., 2010). Vale ressaltar que a preocupação com as mudanças drásticas do clima nos últimos anos, está diretamente ligada aos desastres ambientes que estão ocorrendo com mais frequência, como: tsunamis, furacões, frios extremos, escassez hídrica, dentre outros.

O conhecimento das variáveis climáticas é de fundamental importância não só para diferenciar o clima do continente, mas também para o planejamento de diversas atividades produtivas, tais como agricultura, pecuária, dentre outras. (Freitas et al., 2010).

A precipitação de um modo geral pode ser distinguida como o regresso ao solo, do vapor de água que se condensou, e se transformou em gotas de extensões satisfatórias para romper a força da gravidade (Sousa et al, 2015). Esse ciclo da água entre a atmosfera e o solo, tem particularidades e 
feições quantitativos para cada local, mas sua distribuição anual é irregular em todas as regiões do globo terrestre (Lira et al., 2006; Silva et al., 2010).

A disponibilidade hídrica é a informação básica de apoio à decisão sobre a outorga de direito de uso de recursos hídricos de determinada bacia hidrográfica, que tem como objetivos "assegurar o controle quantitativo e qualitativo dos usos da água e o efetivo exercício dos direitos de acesso à água", conforme disposto no Artigo 11 da Lei Federal n. ${ }^{\circ}$ 9.433/1997. Ainda segundo esta lei, no seu Artigo 7. ${ }^{\circ}$, Parágrafo III, a outorga deve estar vinculada a estudos referentes ao "balanço entre disponibilidades e demandas futuras dos recursos hídricos, em quantidade e qualidade, com identificação de conflitos potenciais".

\section{Modificação das condições climáticas por ações antrópicas}

A interferência antrópica no meio ambiente, é considerado um dos principais fatores que influenciam nas mudanças climáticas e nos regimes de temperatura e precipitação pluviométrica. Isso ocorre devido aos grandes desmatamentos e queimadas, além da crescente urbanização sem planejamento adequado que vem ocorrendo nas últimas décadas (Karl et al, 1988).

$\mathrm{O}$ aquecimento global tem causado drásticas mudanças nas condições climáticas. Tal evento tem gerado grandes preocupações em nível mundial, pois as alterações ocorridas nas condições climáticas podem afetar direta e indiretamente a demanda de água para todo o meio ambiente (Leonidas, 2011; Filho et al, 2015). Além de intensificar os desastres naturais que ultimamente vem ocorrendo com mais frequência e com proporções catastróficas.

Os recursos hídricos são um dos elementos mais relevantes na discussão da crise ambiental que já é um problema enfrentado por toda a humanidade (Silva et al, 2013). Dentre todos os recursos naturais que estão à disposição do homem, a água é considerada a mais importantes, por ser indispensável para a sobrevivência do planeta Terra (Lira e Cândido, 2013). Assim, configura-se a imprescindível e vital importância de sua conservação, preservação e utilização racional por parte da espécie humana.

De acordo com Alves (2004, p. 22), “a crise da água está inserida em um contexto maior que é a crise ambiental mundial, sendo esta de caráter complexo e multidimensional e submetida a vários posicionamentos de ordem moral, intelectual e ética". Neste contexto, pode-se constatar que a crise hídrica está diretamente relacionada a problemas como a carência 
dos serviços de saneamento básico, o aumento da pobreza, o crescimento demográfico desordenado nos grandes centros urbanos, a falta de acesso à água potável, contaminação dos recursos hídricos, a disseminação de doenças e as mudanças climáticas locais, dentre outros (Silva et al, 2010).

A contaminação dos recursos hídricos que vem crescendo assustadoramente nas últimas décadas, em todo o mundo. $\mathrm{O}$ abastecimento das grandes metrópoles exige que a água seja deslocada de regiões cada vez mais distantes dos centos urbanos. No decorrer desse processo, os recursos hídricos acabam sendo comprometidos (Rebouças, 1997). Abastecer a humanidade com água potável de qualidade será o grande desafio para os próximos anos.

Atualmente, o aumento de impactos ambientais decorrentes do excesso ou falta de chuva têm causado diversos transtornos à população dos centros urbanos. Vale ressaltar que nestes locais vivem a maior parte da população brasileira (Nunes e Calbete, 2000).

\section{Caracterização da área de estudo}

O semiárido brasileiro é composto por 1,113 municípios, ocupando uma área de $982.563,3 \mathrm{~km}^{2}$ e uma população de aproximadamente 47 milhões de habitantes. Cerca de 89,5\% encontram-se na região Nordeste (IBGE, 2015). Ressaltando que as regiões semiáridas brasileiras têm um expressivo déficit hídrico, apresentando médias anuas idênticas ou inferiores a $800 \mathrm{~mm}$ e um indicador de insolação médio de $2.800 \mathrm{~h} / \mathrm{ano}$.

A escassez de água no semiárido brasileiro e principalmente na região nordeste é um problema que as pessoas que residem nessas áreas enfrentam ano após ano (SOUSA et al, 2017). Essa região é caracterizada por ter: quase oito meses de ausência de chuvas que ocorrem anualmente, secas periódicas e cheias frequentes dos rios intermitentes, solos arenosos, rasos, salinos e pobres em nutrientes essenciais ao desenvolvimento das plantas. A vegetação básica do Sertão é a caatinga, que apresenta grande variedade de formações, todas adaptadas à prolongada estação seca (Aldo, 1997).

Nas regiões semiáridas as precipitações ainda representam a única fonte de realimentação dos cursos dos rios e aquíferos, principalmente os localizados na região Nordeste. Além da grande perda de água causada devido os solos serem em sua maioria rasos e arenosos, há também um 
elevado fluxo de evaporação da água ocasionada pelas elevadas temperaturas da região (Albiero et al., 2015).

$\mathrm{Na}$ buscar por soluções para a escassez de água, a população do Semiárido Nordestino, iniciou em 1980 por meio dos investimentos dos órgãos governamentais, a construir açudes públicos, barreiros, cisternas e poços artesianos e de fundação a fim de armazenar a água que seria utilizada posteriormente para o abastecimento das populações, rebanhos e plantios (Assunção, Livingstone, 2015).

A Região Metropolitana do Cariri (RMC) está localizada no estado brasileiro do Ceará (Figura 1) e é constituída por nove municípios: Juazeiro do Norte, Crato e Barbalha, além dos municípios de Caririaçu, Farias Brito, Jardim, Missão Velha, Nova Olinda e Santana do Cariri, abrangendo uma área de $5.460 \mathrm{~km}^{2}$. Tem como área de influência a região sul do Ceará e a região da divisa entre o Ceará e os estados de Pernambuco, Paraíba e Piauí. A RMC tem uma população estimada em 601.817 mil habitantes (IBGE, 2017) e o PIB da região está em torno 7 bilhões de reais (IBGE, 2011).

Figura 1: Localização da Região Metropolitana do Cariri
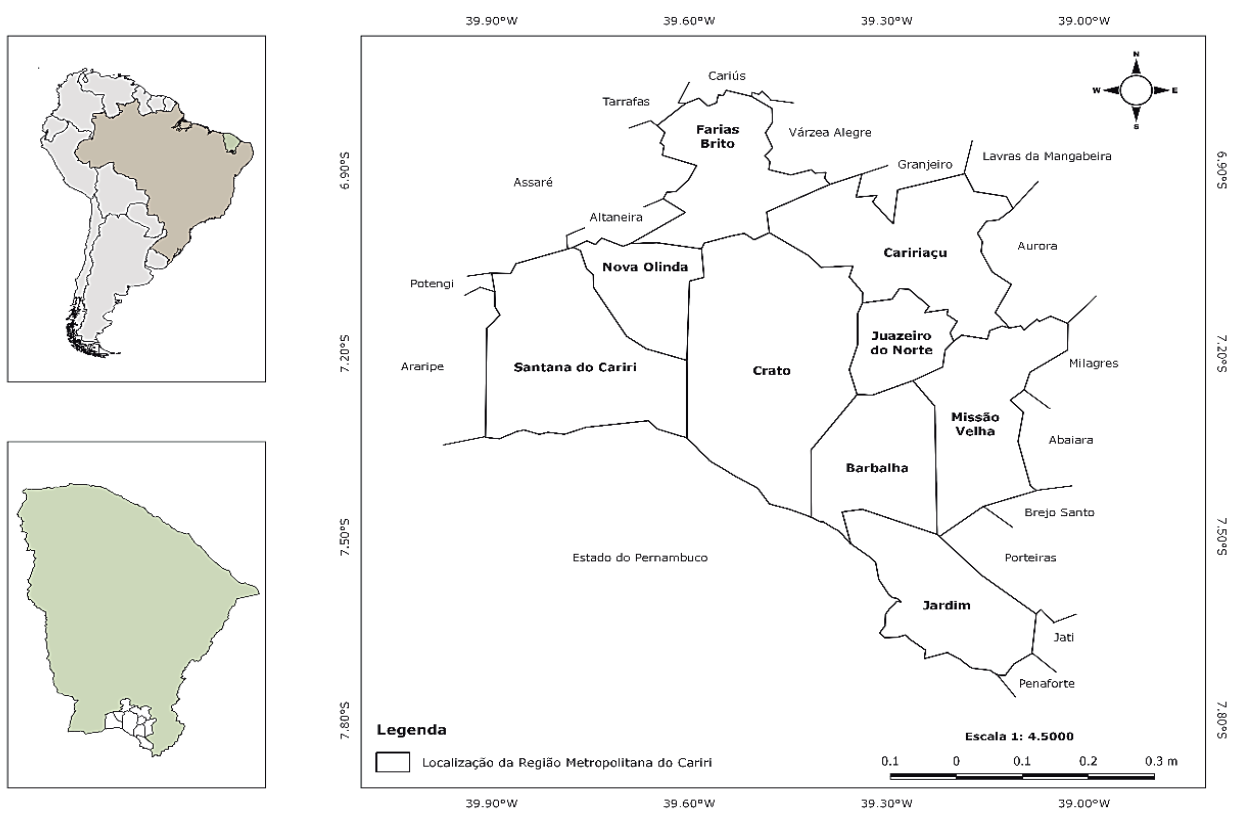

Fonte: IBGE, 2018, Organização: Autor, 2018. 
A região tem como bacias hidrográficas a do Alto Jaguaribe e Salgado. Em relação ao relevo, apresenta feições de Chapa do Araripe, Depressões sertanejas e Maciços Residuais. O solo bem definido e bastante diversificado, com predominância de ordens de Neossolos, Litossolos, Nitossolos e Argilossolos. Os quatro tipos de solos apresentam boa fertilidade natural e permeabilidade (Figura 2), entretanto estas características podem variar de acordo com as localidades e interferências antrópicas (Embrapa (2006); IBGE 2018)).

A região do Cariri é reconhecida nacionalmente como o "Oásis do Sertão", devido as suas caracterizas singulares, dentre as demais regiões do Ceará. Regionalistas apaixonados veem o Cariri como o maior polo da cultura popular nordestina do interior ou do Nordeste em geral.

O sistema hídrico da Região Metropolitana do Cariri é composto por mananciais de superfície, poços profundos e alguns poços particulares, além de algumas captações em pequenos mananciais e nascentes. Atualmente, esse sistema é capaz de garantir o abastecimento da região (que inclui a população residente, a população flutuante e as atividades econômicas) sem maiores problemas, revelando um quadro de abundância de recursos hídricos na região.

Os tipos de climas predominantes na região são o Tropical Quente Semiárido, Tropical Quente Semiárido Brando e tropical Quente Subúmido. As temperaturas anuais variam entre $22^{\circ}$ a $28^{\circ}$ e pluviosidade anual total que pode chegar a $8.625,8 \mathrm{~mm}$ (FUNCEME, 2018). Vale ressaltar que tais características podem variar de acordo com a localidade analisada.

Já o período chuvoso estende-se entre os meses de janeiro a abril e o período seco de maio a dezembro. Porem as chuvas são irregulares em curto espaço de tempo. Entretanto possui diversas características que favorecem as práticas de agricultura, pecuária e lazer, como abundancia de água subterrâneas, fontes naturais, riachos superficiais, trilhas ecológicas e turismo religioso (Lopez, 2005). Além de contar com reservatórios de grande porte, boa fertilidade natural e temperaturas médias constantes (Figura 3). 


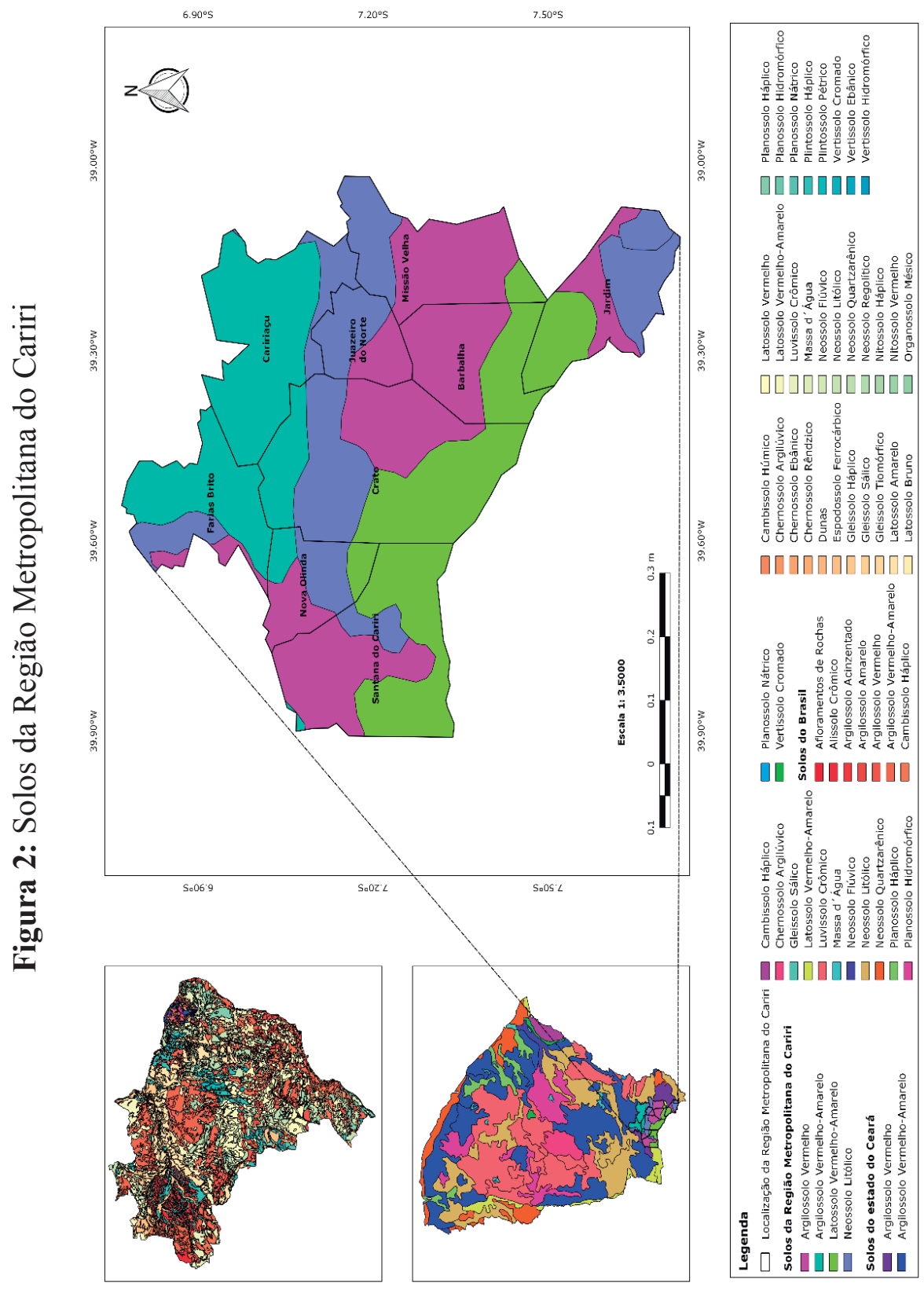



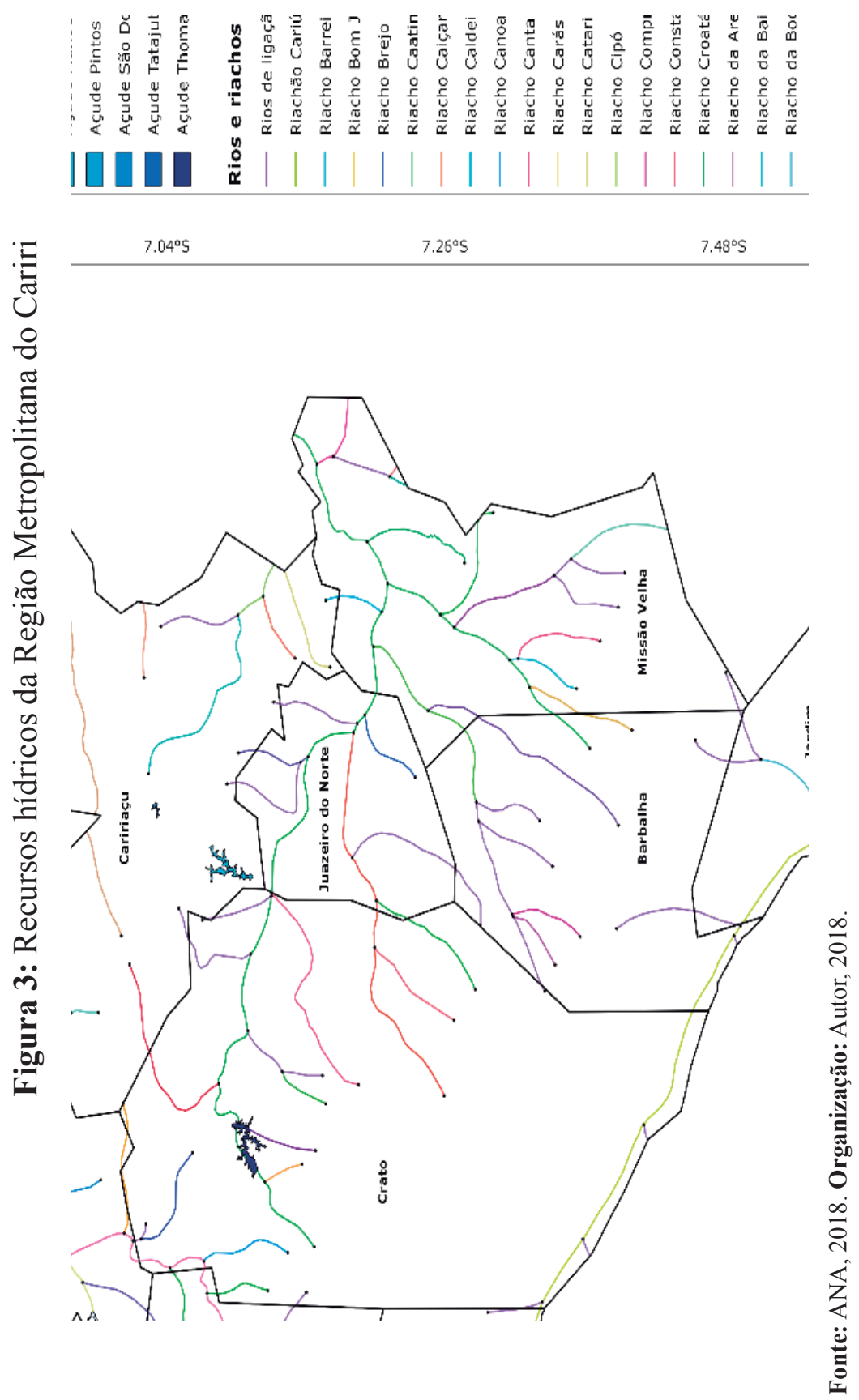

328 Revista Geográfica de América Central. No 63(2)

ISSN 1011-484X • e-ISSN 2215-2563 / Julio-diciembre 2019

Doi: http://dx.doi.org/10.15359/rgac.63.2-12 


\section{Metodologia}

Entre os meses de janeiro de 2018 a fevereiro de 2018, foi realizada uma pesquisa junta ao órgão da Fundação Cearense de Meteorologia e Recursos Hídricos - FUNCEME, do governo do Ceará e um levantamento dos postos pluviométricos da região (Figura 4).

Figura 4: Localização dos postos pluviométricos da Região Metropolitana do Cariri
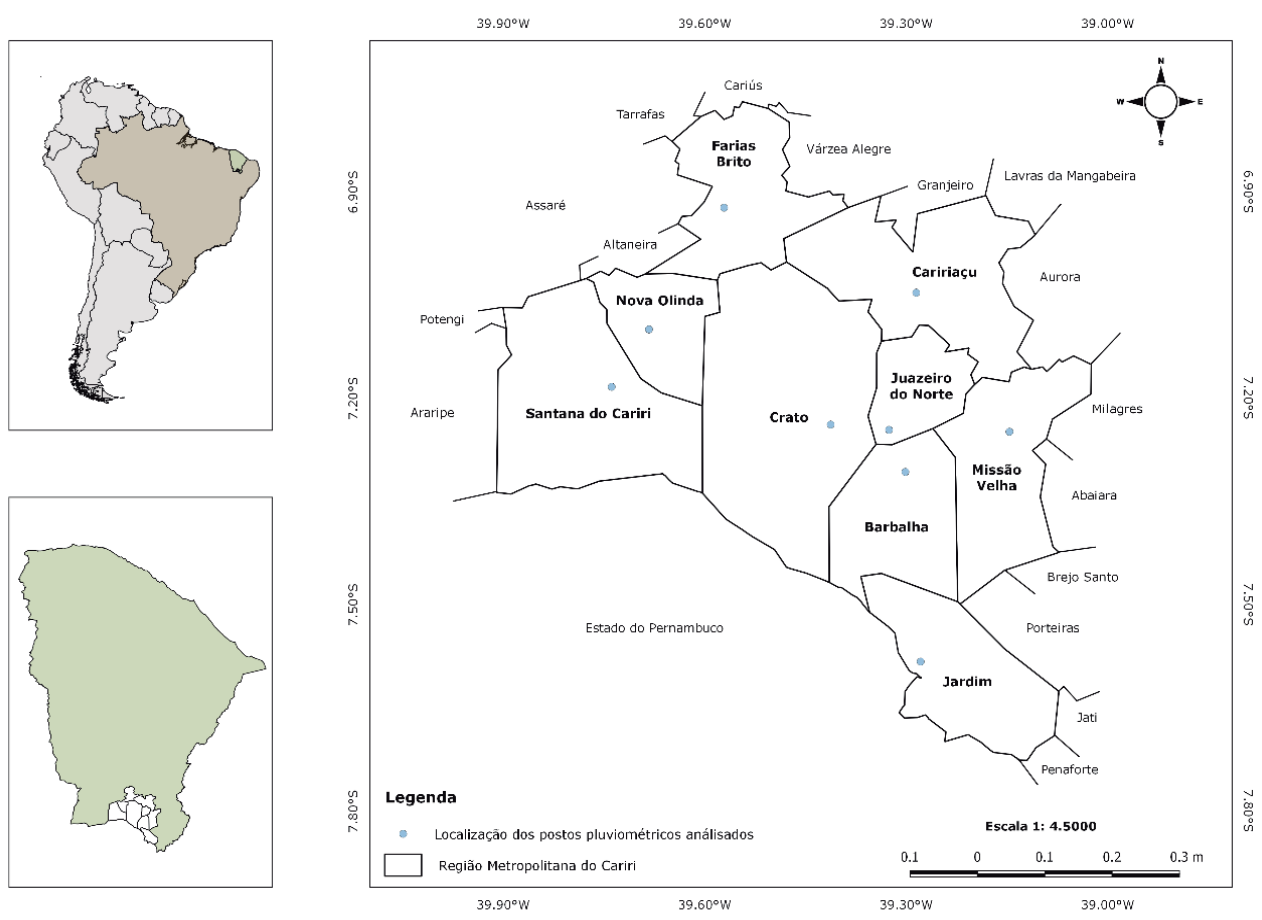

Fonte: IBGE, 2018.

Organização: Autor, 2018.

Posteriormente foram levantados junto ao Instituto de Pesquisa e Estratégia Econômica do Ceará - IPECE, Instituto Brasileiro de Geografia e Estatística - IBGE, entre outros, dados relativos a população da região e seus aspectos terreais, econômicos, sociais e suas variais climáticas. Após estes estudos preliminares, foram realizadas pesquisas bibliográficas, com vistas a montar um referencial completo sobre a região de estudo. 
Análise dos dados foi feita mediante a organização dos mesmos em quadros e tabelas de maneira a tornar possível a obtenção das informações relevantes para a análise temporal do comportamento da precipitação pluviométrica na Região Metropolitana do Cariri.

A metodologia utilizada para o desenvolvimento da pesquisa foi baseada em Monteiro et al. (2013), onde é selecionado um posto pluviométrico de uma determinada região e, em seguida, verifica-se o comportamento dos dados utilizando alguns parâmetros da estatística descritiva, como: média, máximo, mínimo e desvio padrão.

Vale ressaltar que o estudo de séries de chuvas é fundamental para o manejo dos recursos hídricos, desenvolvimento de projetos de convivência com o semiárido e melhores períodos para o desenvolvimento da agropecuária. Este método de análise permite avaliar todas as características pluviométricas de uma determinada região (Costa, Becker e Brito, 2013; Filho e Araújo, 2015).

Realizou-se o levantamento pluviométrico mensal de uma série de dados, provenientes da Fundação Cearense de Meteorologia e Recursos Hídricos - FUNCEME, correspondentes ao período de 1987 a 2017 da referida área de estudo. Os postos adotados para análise são monitorados diariamente pela instituição (Quadro 1).

Quadro 1: Coordenadas dos postos pluviométricos da Região Metropolitana do Cariri

\begin{tabular}{llc}
\hline \multirow{2}{*}{$\begin{array}{c}\text { Municípios da Região Metro- } \\
\text { politana do Cariri }\end{array}$} & \multicolumn{2}{c}{ Coordenadas dos postos pluviométricos } \\
\cline { 2 - 3 } Barbalha & Latitude & Longitude \\
\hline Caririaçu & $-7.307222^{\circ}$ & $-39.301639^{\circ}$ \\
Crato & $-7.046611^{\circ}$ & $-39.285417^{\circ}$ \\
Farias Brito & $-7.238333^{\circ}$ & $-39.412778^{\circ}$ \\
Jardim & $-6.923083^{\circ}$ & $-39.571583^{\circ}$ \\
Juazeiro do Norte & $-7.583000^{\circ}$ & $-39.278917^{\circ}$ \\
Missão Velha & $-7.246028^{\circ}$ & $-39.326000^{\circ}$ \\
Nova Olinda & $-7.248778^{\circ}$ & $-39.146639^{\circ}$ \\
Santana do Cariri & $-7.100000^{\circ}$ & $-39.683356^{\circ}$ \\
\hline
\end{tabular}

Fonte: FUNCEME, 2018.

Organização: Autor, 2018. 
Os dados coletados foram distribuídos em quadros e tabelas de maneira a tornar possível a obtenção de informações relevantes sobre a pluviometria da região. Posteriormente realizou-se cálculos de parâmetros, como: média, máximo, mínimo e desvio padrão.

Baseado nestas informações foi possível conhecer as características pluviométricas da Região Metropolitana do Cariri -CE.

\section{RESULTADOS E DISCUSSÕES}

A distribuição dos valores pluviais das médias mensal e anual, com base nos dados da série histórica de 1987 a 2017, registradas em 9 estações pluviométricas distribuídos na área em estudo, apresenta uma variação significativa da precipitação.

O monitoramento dessas chuvas que ocorrem em pulsos ou irregularmente são feitos por pontos pluviométricos que se refere à quantidade de chuva por metro quadrado em determinado local e em determinado período e a partir desses dados é possível calcular o total da precipitação de um município, estado ou pontos específicos.

A Figuras 5 apresenta as precipitações pluviométricas anuais totais, que compõem o período de chuvas da região.

Através dos dados apresentados no gráfico anterior, pode-se destacar que as precipitações anuais na RMC variam muito no decorrer dos anos analisados. Dentre os municípios que apresentaram os maiores índices pluviométricos, destacam-se Caririaçu que no ano de 2008 alcançou 1632,0 mm e Santana do Cariri com 1612,1 mm em 1996. Já em relação aos menores défices pluviométricos, temos as cidades de Nova Olinda com 359,0 mm em 2016 e Jardim com 177,0 mm em 2017.

No decorrer dos 31 anos analisados, os municípios Crato e Barbalha apresentam um acumulo hídrico invejável, com 33.171,4 mm e 32.339,9 $\mathrm{mm}$, respectivamente. Em contrapartida, as regiões que acumulam uma parcela menor de pluviosidade são Nova Olinda com 24.733,3 mm e Jar$\operatorname{dim} \operatorname{com} 20.703,3 \mathrm{~mm}$.

Chuvas acima da média podem causar graves consequências as populações que residem em áreas de risco, cidades mal planejadas, dentre outros. Dentre os riscos destacam-se os deslizamentos de encostas, inundações de cidades, perda de bens matérias e em casos mais graves a morte de pessoas e animais (PBMC, 2016). 
Figura 5: Precipitação histórica anual da Região Metropolitana do Cariri (1987-2017)

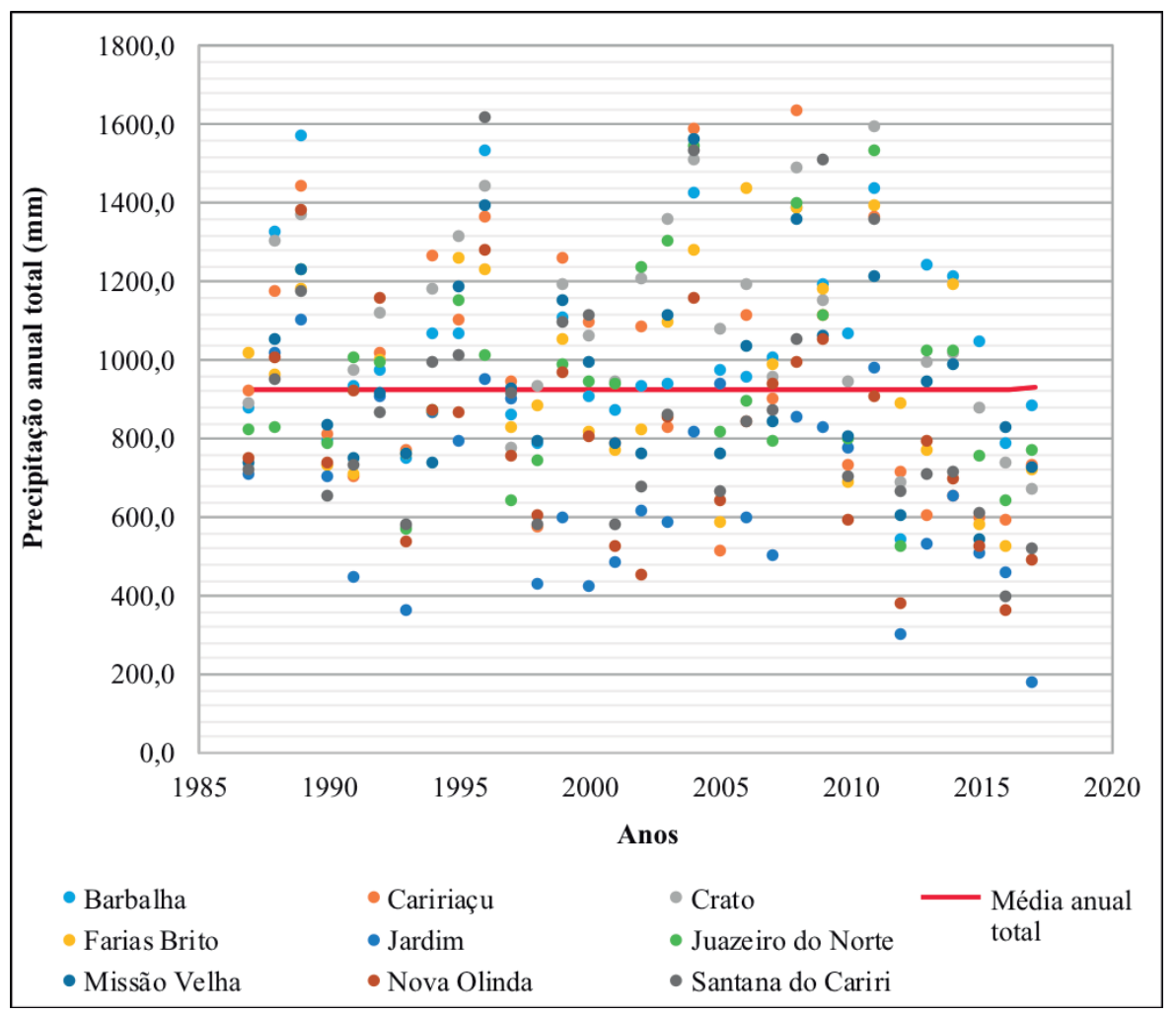

Fonte: FUNCEME, 2018.

Organização: Autor, 2018.

Outro ponto importante refere-se ao aumento das doenças no período de chuvas intensas. Dentre as enfermidades mais encontradas na RMC destacam-se: dengue, hanseníase, leishmaniose visceral e tuberculose (IPECE, 2018).

Os dados referentes a taxe de cobertura de água e esgotos podem ser observados por meio da Quadro 02. Dentre os munícipios que compõem a RMC, Barbalha apresenta as melhores taxas de cobertura básica com $99,65 \%$ de água e $53,96 \%$ de esgoto. 
Quadro 02: Taxa de cobertura urbana de água e esgoto da RMC

\begin{tabular}{lcc}
\hline $\begin{array}{c}\text { Municípios da Região } \\
\text { Metropolitana do Cariri }\end{array}$ & Taxa de água (\%) & Taxa de esgoto (\%) \\
\hline Barbalha & $99,65 \%$ & $53,96 \%$ \\
Caririaçu & $100 \%$ & $*$ \\
Crato & $98 \%$ & $33 \%$ \\
\hline Farias Brito & $99,10 \%$ & $*$ \\
\hline Jardim & $99,73 \%$ & $9,87 \%$ \\
Juazeiro do Norte & $99,05 \%$ & $37,24 \%$ \\
Missão Velha & $99,54 \%$ & $9,57 \%$ \\
\hline Nova Olinda & $99,76 \%$ & $*$ \\
\hline Santana do Cariri & $99,73 \%$ & $*$ \\
\hline
\end{tabular}

* Não apresentam dados referentes a cobertura de esgoto municipal.

Fonte: IPECE, 2018.

Organização: Autor, 2018.

Pode-se destacar que apesar de todos os municípios terem elevada cobertura de ligações de água à suas residências, a taxa de ligações a rede de esgotamento sanitário é mínima e totalmente inexistente de outras regiões. Assim, em períodos com elevados índices de precipitação, ocorre uma poluição generalizada dos centros urbanos e recursos hídricos da RMC.

Vale ressaltar que a maioria da população despeja seus efluentes em fossas sépticas no inteiro de suas morarias e a céu aberto, poluindo todo o meio ambiente e elevando os riscos de contaminação em pedidos de chuva.

Segundo dados da FUNCEME (2017) o Ceará passou por uma das maiores secas já registradas desde 1910, no ano de 2016, levando o estado a um período de calamidade hídrica. As principais consequências foram a diminuição drástica dos níveis de águas nos reservatórios, morte de animais, êxodo rural, queimadas, dentre outros. Vale ressaltar que a seca na região se agravou devido níveis baixos de chuvas registados de 2013 a 2015.

De acordo com Neves (2002), as principais causas da seca do Nordeste são de ordem naturais. Pois a região está localizada numa área em que as chuvas ocorrem poucas vezes durante o ano e irregularmente. Assim, esta área recebe pouca influência de massas de ar úmidas e frias vindas do Sul durante o ano. Logo, permanece durante muito tempo, no sertão 
nordestino, apenas uma massa de ar quente e seca, não gerando precipitações pluviométricas.

A precipitação mensal total de todos os meses no decorrer dos 31 anos analisados (Figura 6) demonstram que a RMC, apresenta um período chuvoso que se estende entre os meses de janeiro a abril e o período seco de maio a dezembro.

Figura 6: Precipitação histórica mensal da Região Metropolitana do Cariri (1987-2017)

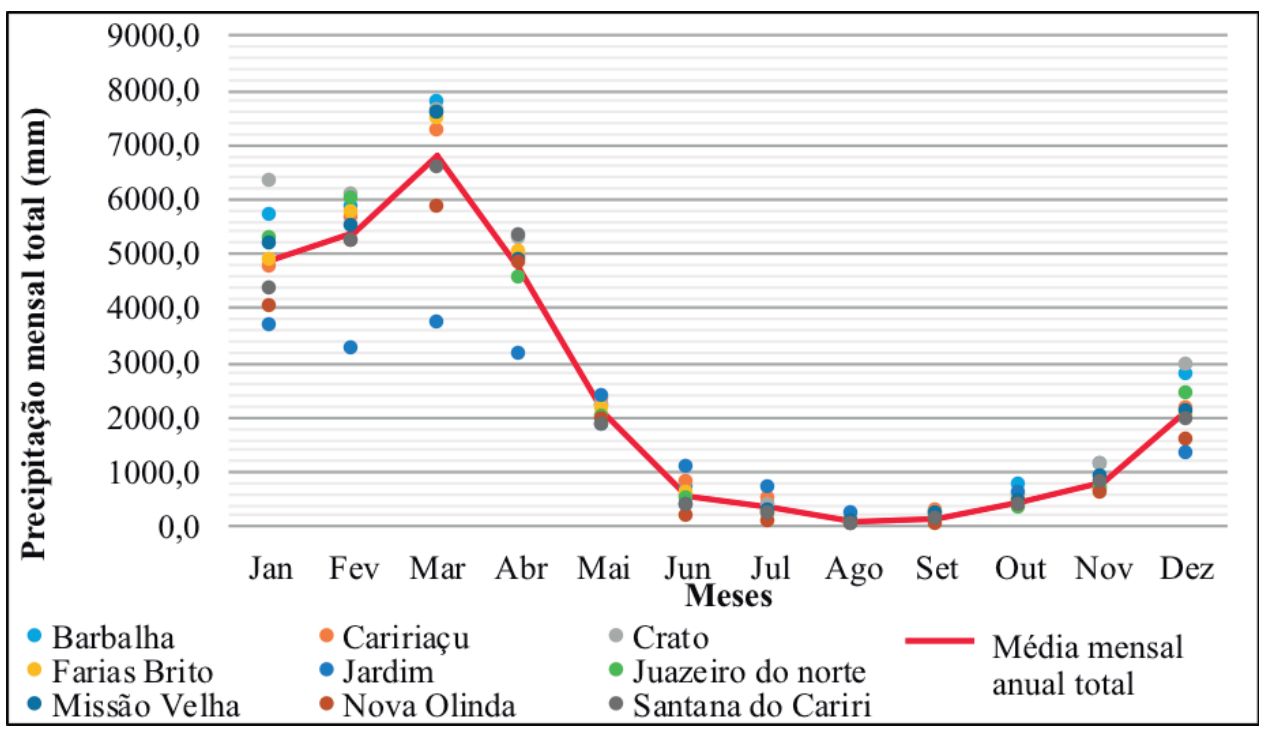

Fonte: FUNCEME, 2017.

Organização: Autor, 2018.

Os meses que apresentaram os maiores índices pluviométricos dentre os anos analisados foram fevereiro e março com um total de $40.407,7 \mathrm{~mm}$ e $61.254,6 \mathrm{~mm}$, simultaneamente.

Em relação ao desvio padrão dos municípios, o maior valor foi observado em Caririaçu, indicando que essa foi a região que as precipitações anuais mais se distanciaram da média durante os 31 anos. Já o menor valor foi observado em Jardim (Quadro 3). 
Quadro 3: Desvio padrão anual total da RMC (1987-2017)

\begin{tabular}{cc}
\hline Municípios da Região Metropolitana do Cariri & Desvio padrão (mm) \\
\hline Barbalha & $247,0 \mathrm{~mm}$ \\
\hline Caririaçu & $311,8 \mathrm{~mm}$ \\
Crato & $267,7 \mathrm{~mm}$ \\
\hline Farias Brito & $254,8 \mathrm{~mm}$ \\
\hline Jardim & $232,9 \mathrm{~mm}$ \\
\hline Juazeiro do Norte & $260,7 \mathrm{~mm}$ \\
Missão Velha & $240,0 \mathrm{~mm}$ \\
Nova Olinda & $257,3 \mathrm{~mm}$ \\
Santana do Cariri & $309,4 \mathrm{~mm}$ \\
\hline
\end{tabular}

Fonte: Autor, 2018.

Vale ressaltar que o desvio padrão é considerado um parâmetro importantíssimo, pois é muito usado em estatística para indicar o grau de variação de um conjunto de elementos. Podendo ser aplicado em diferentes áreas de estudo como a climatologia (Wolffenbüttel, 2006).

\section{Considerações finais}

Com base no exposto e avaliando-se o regime pluviométrico durante os anos de 1987 a 2017, na RMC, registrou-se um período seco em 2016 e 2017 na maioria dos munícios, com precipitação anual bem abaixo da média para a serie adotada, o que possivelmente afetou no desenvolvimento das atividades industriais e agropecuárias da região.

Identificou-se de a RMC apresenta graves falhas em relação a sustentabilidade hídrica, pois apesar das chuvas fartas no decorrer dos anos, a população das mesmas não tem conscientização. Dentre os problemas encontrados destacam-se: esgotos a céu aberto, lixões, efluentes domésticos e industriais despejados em córregos de rios, ligações clandestinas as redes de água, dentre outros.

Espera-se que esta pesquisa venha contribuir com a sustentabilidade hídrica da Região Metropolitana do Cariri - CE e que seja fonte de informação para subsidiar outras pesquisas nesta área. Dentre as recomendações 
para trabalhos futuros, sugere-se que esta metodologia seja aplicada em outras regiões para identificação das características pluviométricas, afim auxiliar no planejamento adequado dos recursos hídricos.

\section{Referências}

Agência Nacional de Águas (ANA) (2018). Metadados. Recuperado: http://metadados. ana.gov.br/geonetwork/srv/pt/main.home.

Albiero, Daniel. et al. (2015). Tecnologias agroecológicas para o Semiárido. Fortaleza: Edição do Autor. (Pp 216). Recuperado: http://www. ppgea.ufc.br/images/diversos /Tecnoloem: giasAgroecologicas.pdf. Aldo, C. R. (1997). Água na região Nordeste: desperdício e escassez. Revista Scielo. Recuperado: http://www.scielo.br/pdf/ea/v11n29/ v11n29a07.

Alves, A. O. (2004). Planejamento ambiental urbano na Microbacia do Córrego da Colonia Mineira - Presidente Prudente/SP. Presidente Prudente: UNESP/FCT, 2004. Dissertação de Mestrado. (Pp 128). Recuperado: https://alsafi.ead.unesp.br/handle /11449/92842.

Assunção, L. M.; Livingstone, I. (1993). Desenvolvimento inadequado: construção de açudes e secas no sertão do Nordeste. Revista Brasileira de Economia, v. 47, n. 3. (Pp. 2-24). Recuperado: http:// bibliotecadigital.fgv.br/ojs/index.php/rb e/artic le/view / 582/7932.

Brasil. (1997). Lei Federal n. ${ }^{\circ}$ 9.433: Institui a Política Nacional de Recursos Hídricos, cria o Sistema Nacional de Gerenciamento de Recursos Hídricos, regulamenta o inciso XIX do artigo 21 da Constituição Federal e altera o artigo $1 .^{\circ}$ da Lei Federal n. ${ }^{\circ} 8.001$, de 13 de março de 1990, que modificou a Lei Federal n. ${ }^{\circ}$ 7.990, de 28 de dezembro de 1989. Brasília. Brasil. Recuperado: http://www. mma.gov.br/port/srh/politica/legisla cao/lei9433.html.

Empresa Brasileira de Pesquisa Agropecuária (EMBRAPA). (2006). Centro Nacional de Pesquisa de Solos. Sistema brasileiro de classificação de solos. Rio de Janeiro, Brasil

Feil, A. A.; Haetinger, C. (2014). Previsão de consumo de água via modelagem matemática de sistema de abastecimento de água. Revista DAE, no 195. Recuperado: http://revistadae.com.br/artigos/ artigo_edicao_195_n_1513.pdf. 
Filho, A. I. et al. (2015). Influência das variáveis climáticas sobre a evapotranspiração. Gaia scientia, v. 9, n. 1. (Pp. 62-66). Recuperado: http://www.okara.ufpb.br/ojs/index. php/gaia/article/ viewFile/24072/13286.

Filho, J. A. S., Araújo, S. C. (2015). Análise temporal do comportamento da precipitação pluviométrica no município de Pombal - PB. II Workshop Internacional sobre água no Semiárido. Anais, v. 1. Recuperado: http://www.editorarealize.com.br/revistas/aguano semiarido /anais.php.

Francisco, C. N. (2014). Subsídios à gestão sustentável dos recursos hídricos no âmbito municipal - O caso de Angra dos Reis, RJ. Tese de Doutorado. Universidade Federal Fluminense, Niterói RJ. 2004. Recuperado: http://www.meusiteantigo.uff.br/ cristiane/ Documentos/Tese\%20CNF.pdf. (Pp 179).

Freitas, A. C. V., Franchito, S. H., Rao, V. B. (2010). A Importância dos dados das variáveis climáticas nas pesquisas em geografia: Um estudo de caso empregando a precipitação pluviométrica. Climep - Climatologia e Estudos da Paisagem, Rio Claro, v. 5, n. 1. (Pp. 5-18). Recuperado: http:/www.periodicos.rc.biblioteca.unesp.br/ index.php/climato logia/index.

Fundação Cearense de Meteorologia e Recursos Hídricos (FUNCEME). (2018). Dados dos postos pluviométricos do estado do Ceará. Recuperado: http://www.funceme. br/produtos/script/chuvas/ Download_de_series_historicas/DownloadChuvasPublico.php.

Fundação Cearense de Meteorologia e Recursos Hídricos. (2017). Ceará passa pela pior seca prolongada desde 1910. Recuperado: http://www. funceme.br/index.php/comunicacao/ noticias/740-cear\%C3\%A1passa-pela-pior-seca-prolongada-desde-1910\#site.

Instituto Brasileiro de Geografia e Estatística (IBGE). (2011). Produto Interno Bruto dos Municípios 2011. Recuperado: https://ww2.ibge. gov.br/home/estatistica/economia/pibmunicipios/2011/default.shtm. Instituto Brasileiro de Geografia e Estatística (IBGE). (2015). Áreas especiais. Recuperado: https://ww2.ibge.gov.br/home/geociencias/ geografia/semiarido.shtm?c=4. 
Sostenes Gomes de Sousa Análisis temporal del comportamiento de la precipitación pluviométrica en la Región Metropolitana de Cariri (Ce), Brasil

Instituto Brasileiro de Geografia e Estatística (IBGE). (2017). Cidades. Recuperado: https:/cidades.ibge.gov.br/xtras/ uf.php?lang $=\& \operatorname{coduf}=23 \&$ search $=$ ceara.

Instituto Brasileiro de Geografia e Estatística (IBGE). (2018). Base de dados. Recuperado: https://downloads.ibge.gov.br/.

Instituto de Pesquisa e Estratégia Econômica do Ceará (IPECE). (2018). Perfil municipal. Recuperado: http://www.ipece.ce.gov.br/index. php/perfil-municipal/

Karl, T. R., Diaz, H. F., Kukla, G. (1988). Urbanization: its detection and effect in the United States climate record. Journal of Climate, v. 1 n. 11. (Pp. 1099-1123). Recuperado: http: //journals. ametsoc.org/doi/abs/10.1175/15200442\%281988\%29001\% 3C1099\%3AUIDAEI\%3E2.0.CO\%3B2.

Lira, W. S., Cândido, G. A. (2013). Gestão sustentável dos recursos naturais: uma abordagem participativa. Campina Grande: EDUEPB. (Pp 326).

Lopez, C. R. M. et al. (2005). Qualidade das águas subterrâneas no vale do cariri - área em Crato, Juazeiro do Norte e Barbalha - estado do Ceará, brasil. XIV Encontro Nacional de Perfuradores de Poços e II Simpósio de Hidrogeologia do Sudeste, Anais. Recuperado: https:// aguassubterraneas.abas.org/asubterraneas/issue/view/1190.

Monteiro, D. R. et al. (2013). Levantamento pluviométrico do município de Patos-PB nos últimos 16 anos. In: Workshop Internacional sobre Água no Semiárido Brasileiro, Ed. Realize, v. 1. (Pp. 1-5).

Nascimento, D. C. (2015). Região Metropolitana do Cariri - CE: um cenário de incertezas quanto à gestão, planejamento e finalidades. XI - Encontro Nacional da Anpege, Anais. Recuperado: http://www. enanpege.ggf.br/2015/anais/arquivos/20/560.pdf.

Neves, F. C. (2002). Seca - história e cotidiano. Brasil: Demócrito Rocha. (Pp 134).

Nunes, L. H., Calbete, N. O. (2000). Variabilidade pluviométrica no Vale do Paraíba Paulista. In: Congresso Brasileiro de Meteorologia, Rio de Janeiro. (Pp. 3987-3994).

Oliveira, L. A., Faleiros, F. E., Santos, J. A. S. (2012). Análise do condicionamento da altitude nas variáveis climáticas de temperatura e precipitação na Mesorregião do Triangulo Mineiro e Alto Paranaíba. 
Revista geonorte, Ed. 2, v. 1, n. 5. (Pp. 325-335). Recuperado: http:// www.periodicos.ufam.edu.br/revista-geonorte/article/view/2361.

Painel Brasileiro de Mudanças Climáticas (PBMC). (2016). Mudanças Climáticas e Cidades. Relatório Especial do Painel Brasileiro de Mudanças Climáticas. Rio de Janeiro, Brasil. (Pp 116). Recuperado: http://www.pbmc.coppe.ufrj.br/documentos/Relato rio_UM_v102017-1.pdf.

Rebouças, A. C. (1997). Água na região Nordeste: desperdício e escassez. Revista Estudos Avançados, v. 11, n. 29. (Pp. 127-154). Recuperado: http://www.revistas.usp.br/eav/ article/view/ 8976/10 528.

Ripoli, G., Ferreira, D. H. L. (2014). Tendências dos parâmetros hidroclimáticos no rio Paraíba do Sul. Anais do IV Encontro de Iniciação em Desenvolvimento Tecnológico Inovação e XIX Encontro de Iniciação Cientifica. Recuperado: http://webcache. googleusercontent. $\mathrm{com} / \mathrm{search}$ ? $\mathrm{q}=\mathrm{c}$ ache: A 2 eXoEA ubEwJ : m tcm $16 \mathrm{c}$. $\mathrm{sid}$. i n pe.br/a r chive.c gi/sid.in pe.br/ ePrint\%4080/2005/05.11.13.21+\&cd=2\&hl=ptBR\&ct=clnk\&gl=br.

Romani, L. A. S. et al. (2010). Mining relevant and extreme patterns on climate time series with CLIPSMiner. Journal of Information and Data Management, v.1, n. 2. (Pp. 245-260). Recuperado: https:// seer.ufmg.br/index.php/jidm/article/view/39.

Silva, J. B., Guerra, L. D., Ioris, A. A. R. (2010). A crise hídrica global e as propostas do Banco Mundial e da ONU para seu enfrentamento. Revista CRONOS, v. 11, n. 2. Recuperado: https://periodicos.ufrn.br/ cronos/article/view/2159/pdf.

Silva, R. M. et al. (2010). Análise da variabilidade espaço-temporal e identificação do padrão da precipitação na Bacia do Rio Tapacurá, Pernambuco. Sociedade \& Natureza, Uberlândia, v. 22, n. 2. (Pp. 357372). Recuperado: http://www.seer.ufu.br/index. php/sociedadenatu reza/article/view/9874.

Silva, V. P. R. et al. (2013). Uma medida de sustentabilidade ambiental: Pegada hídrica. Revista Brasileira de Engenharia Agrícola e Ambiental, v. 17, n. 1. (Pp.100-105). Recuperado: http://www. scielo.br/pdf/rbeaa/v17n1/v17n01a14.pdf.

Sousa, A. S. et al. (2012). Análise da deteriorização ambiental no município de Pombal - PB: Uma Questão sociocultural, política e econômica. 
Revista Verde de Agroecologia e Desenvolvimento Sustentável, v. 7 , n. 2, p. 1-7, 2012.

Sousa, M. I. F., Barbosa, J. J., Costa, C. T. F. (2015). Uma reflexão sobre mudanças climáticas, saúde e meio ambiente no semiárido nordestino. Revista Saúde Meio Ambiente, v. 4, n. 2. (Pp. 61-77). Recuperado: http://www.periodicos.unc.br/index. php/sma/article/ viewFile/802/591.

Sousa, S. G. et al. (2017). Análise socioambiental da produção de goiaba do município de Cariús (CE), brasil. Revista Geográfica de América Central, v. 3, n. 59. (Pp. 249-274). Recuperado em: http://www. revistas.una.ac.cr/index.php/geografica/article/view/100 56/12245.

Wolffenbüttel, Andréa. (2006). O que é? Desvio padrão. Desafios do desenvolvimento. Recuperado: http:/www.ipea.gov.br/desafios/ index.php?option $=$ com_content $\&$ view $=$ article $\&$ id $=2104$ : catid $=28 \&$ Itemid $=23$.

Xavier, R. A., Dornellas, P. C. (2005). Análise do comportamento das chuvas no município de Arapiraca, região agreste de Alagoas. Geografia, v. 14, n. 2. Recuperado: http://www.uel.br/revistas/uel/ index.php/geografia/article/viewFile/6685/6030. 